\title{
Characterization of the Binding of Diarrheagenic Strains of $E$. coli to Plant Surfaces and the Role of Curli in the Interaction of the Bacteria with Alfalfa Sprouts
}

\author{
Cecelia Jeter and Ann G. Matthysse \\ Department of Biology, Coker Hall, University of North Carolina, Chapel Hill 27599-3280, U.S.A.
}

Submitted 28 February 2005. Accepted 20 July 2005.

\begin{abstract}
Diarrheagenic Escherichia coli were able to bind to plant surfaces, including alfalfa sprouts and open seed coats, and tomato and Arabidopsis thaliana seedlings incubated in water. The characteristics of the binding differed with the bacterial strain examined. Laboratory K12 strains of $E$. coli failed to show significant binding to any of the plant surfaces examined, suggesting that some of the genes present and expressed in pathogenic strains and absent or unexpressed in K12 strains may be required for binding to plants. When a plasmid carrying the $m l r A$ gene (a positive regulator of curli biosynthesis) or a plasmid carrying the operons that encode the synthesis of curli $(\operatorname{csg} A-G)$ was introduced into K12 strains, the bacteria acquired the ability to bind to sprouts. CsgA mutants of an avian pathogenic $E$. coli and an 0157:H7 strain showed no reduction in their ability to bind to sprouts. Thus, the production of curli appears to be sufficient to allow K12 strains to bind, but curli are not necessary for the binding of pathogenic strains, suggesting that pathogenic strains may have more than one mechanism for binding to plant surfaces.
\end{abstract}

In the last 10 years, several outbreaks of food poisoning were caused by Escherichia coli O157:H7 and Salmonella spp. carried by alfalfa, mung bean, cress, and radish sprouts (National Advisory Committee on Microbiological Criteria for Foods 1999). The bacteria were found growing with sprouts and may have been introduced as a result of seed contamination or during planting and growth. Where determined, the source of the bacteria appears most likely to have been seed contamination (Mahon et al. 1997; Puohiniemi et al. 1997). Seed (including alfalfa seed) typically carry $10^{4}$ to $10^{5}$ viable bacteria per gram (Prokopowich and Blank 1991). Often, some of the seed carry organisms that are located underneath the seed coat and are not killed by treatment of the seed with disinfectants prior to germination. When seed are germinated, contaminating bacteria grow and spread to neighboring seedlings. A number of adhesive molecules and structures are made by pathogenic, but not laboratory, strains of E. coli. Among these are curli: long, thin, aggregative amyloid fibers made by many pathogenic strains of $E$. coli (Chapman et al. 2002). Similar fibers are made by Salmonella enterica serovar Enteriditis (Collinson et al. 1996; Romling et al. 1998). Most laboratory strains of E. coli do not make curli. Curli are adhesive and bind to animal surface proteins, including fibronectin (Olsen et al. 1989). They have

Corresponding author: A. G. Matthysse; Telephone: 919-962-6941; Fax: 919-962-1625; E-mail: ann_matthysse@unc.edu been shown to mediate internalization of $E$. coli into animal cells (Gophna et al. 2001). Curli potentially could play a role in the binding of pathogenic E. coli to plant surfaces. The genes encoding curli are located in two divergently transcribed operons: $\operatorname{csg} B, \operatorname{csg} A, \operatorname{csg} C$; and $\operatorname{csg} D, \operatorname{csg} E, \operatorname{csg} F, \operatorname{csg} G$ (Chapman et al. 2002; Romling et al. 1998). A plasmid (pRMinv) carrying these two operons has been constructed and shown to confer the ability to synthesize curli on $E$. coli K12 strains (Gophna et al. 2001). We examined the ability of various pathogenic and laboratory strains to bind to alfalfa sprouts and open seed coats, which usually are included with the sprouts in commercial packages. We also examined the ability of curli mutants of pathogenic strains and of laboratory strains containing pRMinv to bind to alfalfa sprouts.

\section{RESULTS}

Binding of laboratory and pathogenic strains to sprouts and open seed coats.

The binding of K12 strains to washed sprouts or open seed coats was examined after 1 and 3 days of incubation. The binding of a variety of diarrheagenic strains of $E$. coli (DEC strains) also was examined. Bacterial strains used in these experiments are listed in Table 1. The strains were chosen to represent different strain serotypes, hosts, and origins in different areas of the world. On washed sprouts and open seed coats, substantial binding was observed for all DEC strains tested after 3 days (Table 2). Between $10^{4}$ and $10^{6}$ bacteria were bound to each sprout or seed coat, the exact number depending on the strain. Less than $5 \%$ of the final number of bacteria recovered from the sprouts was recovered from the second wash of the sprouts or seed coats. Most DEC strains showed significant binding after 1 day, and binding increased between days 1 and 3 (Table 2). Shorter incubation times failed to show significant bacterial binding to plants. Binding of DEC strains 4A and 4C was not detectable after $6 \mathrm{~h}$ of incubation. When binding was examined after 5 days, no significant increase over binding at 3 days was detected for strains $4 \mathrm{~A}, 4 \mathrm{C}$, or $8 \mathrm{D}$ (data not shown). Binding of the other strains at $6 \mathrm{~h}$ or 5 days was not examined. The K12 strains tested showed no significant binding (Table 2).

When the sprouts and open seed coats which had been incubated with bacteria for 3 days were examined in the light microscope, bacteria were observed on the root epidermis and occasionally on the root hairs (Fig. 1). No bacteria were seen bound to the surface of wounded areas although they did appear to enter dead cells or vascular tissue which had openings to the medium. DEC strain 8D was autoaggregative when grown in Luria broth, forming clumps of 10 to $10^{3}$ bacteria (data not 
shown). Unlike the other strains examined which are not autoaggregative, this strain tended to bind to the root surface as aggregates (Fig. 2).

\section{Binding to various plant surfaces.}

Initial measurements of the binding of DEC to plant surfaces were carried out using alfalfa sprouts because this is one of the plants reported to have been a source of these bacteria causing food poisoning. We also examined the binding of K12 and DEC 4A strains to other plants. DEC 4A bound well to tomato and Arabidopsis thaliana seedlings, whereas H39 showed no significant binding (Table 3 ). In order to examine binding of bacteria to plant surfaces in the light microscope with greater sensitivity, a plasmid ( $\mathrm{pBC} g f p$ ) carrying the green fluorescent protein gene behind the lac promoter was introduced into DEC $4 \mathrm{~A}$ and DEC 8D. The presence of the plasmid had no effect on the numbers of bacteria bound as measured on plates with or without chloramphenicol ( $\mathrm{pBC} g f p$ carries resistance to this antibiotic). In the light and fluorescent microscope, binding to the epidermis and root hairs could be detected easily (Figs. 2

Table 1. Bacterial strains and plasmids used in this study ${ }^{\mathrm{a}}$

\begin{tabular}{|c|c|c|c|c|}
\hline Strain or plasmid & Relevant characteristics & Host & Country & Source and reference \\
\hline \multicolumn{5}{|l|}{ Bacterial strain } \\
\hline H39 & K12, prototrophic, Hfr Hayes & $\mathrm{N} \mid \mathrm{A}$ & N/A & American Type Culture Collection \\
\hline DH5 $5 \cdot$ pro & K12 & $\mathrm{N} \mid \mathrm{A}$ & N/A & Clontech \\
\hline ER2267 & $\mathrm{K} 12, \operatorname{kan}^{\mathrm{r}}$ & $\mathrm{N} \mid \mathrm{A}$ & N/A & New England Biolabs \\
\hline DEC $1 \mathrm{~A}$ & O55:H6 & Human & United States & DEC collection \\
\hline $\mathrm{DEC} 2 \mathrm{~A}$ & O55:H6 & Human & Congo & DEC collection \\
\hline DEC4A & $\mathrm{O} 157: \mathrm{H} 7$ & Cow & Argentina & DEC collection \\
\hline DEC4AA & DEC $4 \mathrm{~A} \operatorname{csg} A^{-} \operatorname{carb}^{\mathrm{r}}$ & $\ldots$ & $\ldots$ & This study \\
\hline DEC 4C & $\mathrm{O} 157: \mathrm{H} 7$ & Buffalo & Egypt & DEC collection \\
\hline DEC7D & $\mathrm{O} 157: \mathrm{H} 43$ & $\mathrm{Pig}$ & United States & DEC collection \\
\hline DEC8D & O111:H11 & Human & Cuba & DEC collection \\
\hline DEC9C(C240-52) & $\mathrm{O} 26: \mathrm{HN}$ & Human & Switzerland & DEC collection \\
\hline DEC11D & $\mathrm{O} 128: \mathrm{H} 2$ & Human & United Kingdom & DEC collection \\
\hline DEC13D & O128:H7 & Human & Rwanda & DEC collection \\
\hline DEC15D & $\mathrm{O} 111: \mathrm{H} 21$ & Human & United States & DEC collection \\
\hline $86-24$ & $\mathrm{O} 157: \mathrm{H} 7 \mathrm{sm}^{\mathrm{r}}$ & Human & United States & A. G. Torres \\
\hline $86-24 \mathrm{~A}$ & $86-24 \operatorname{csg} A^{-} \operatorname{carb}^{\mathrm{r}}$ & $\ldots$ & ... & This study \\
\hline$\chi 7122$ & wild type, nal $^{\mathrm{r}}$ & Turkey & United States & R. Curtis (Brown et al. 2001) \\
\hline$\chi 7149$ & $\chi 7122$ rpoS $^{-} \mathrm{nal}^{\mathrm{r}}$ & $\ldots$ & ... & R. Curtis (Brown et al. 2001) \\
\hline$\chi 7185$ & $\chi 7122 \mathrm{mlr}^{-} \mathrm{nal}^{\mathrm{r}}$ & $\ldots$ & $\ldots$ & R. Curtis (Brown et al. 2001) \\
\hline$\chi 7186$ & $\chi 7122 \operatorname{csg}^{-} \operatorname{carb}^{\mathrm{r}} \mathrm{nal}^{\mathrm{r}}$ & $\ldots$ & $\ldots$ & R. Curtis (Brown et al. 2001) \\
\hline \multicolumn{5}{|r|}{ 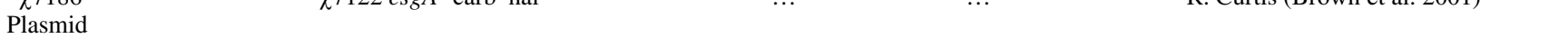 } \\
\hline pUC18 & $a m p^{r}$ & $\ldots$ & $\ldots$ & Lab collection \\
\hline pBCgfp & $\mathrm{cm}^{\mathrm{r}} g f p$ & $\ldots$ & $\ldots$ & Lab collection (Matthysse et al. 1996) \\
\hline pBluescript KS- & $\operatorname{carb}^{\mathrm{r}}$ & $\ldots$ & $\ldots$ & Stratagene \\
\hline pUTgfp & pir-dependent replication, tet $^{\mathrm{r}}, \operatorname{carb}^{\mathrm{r}}$ & $\ldots$ & $\ldots$ & Lab collection (Matthysse et al. 1996) \\
\hline pUTgfp $\Delta X h o$ & pir-dependent replication, carb $^{\mathrm{r}}$ & $\ldots$ & $\ldots$ & This study \\
\hline pBBRmcs-5 & gent $^{r}$ & $\begin{array}{l}\cdots \\
\cdots\end{array}$ & $\ldots$ & M. Kovach (Kovach et al. 1995) \\
\hline pMMB33 & neo $^{r}$ & $\ldots$ & $\ldots$ & E. Ron (Gophna et al. 2001) \\
\hline pRMinv & $\operatorname{csg} A B C D E F G^{+}$neo $^{\mathrm{r}}$ & $\begin{array}{l}\cdots \\
\cdots\end{array}$ & $\begin{array}{l}\cdots \\
\cdots\end{array}$ & E. Ron (Gophna et al. 2001) \\
\hline pYA3404 & $m l r A^{+}$tet $^{\mathrm{r}}$ & $\ldots$ & $\ldots$ & R. Curtis (Brown et al. 2001) \\
\hline
\end{tabular}

Table 2. Binding of Escherichia coli strains to axenic sprouts

\begin{tabular}{|c|c|c|c|c|}
\hline \multirow[b]{3}{*}{ Bacterial strain } & \multicolumn{4}{|c|}{ Mean $\log _{10}$ number of bacteria ${ }^{a}$} \\
\hline & \multicolumn{2}{|c|}{ Per sprout } & \multicolumn{2}{|c|}{ Per seed coat } \\
\hline & 1 day & 3 days & 1 day & 3 days \\
\hline H39 K12 & $0.9 \pm 0.8$ & $1.5 \pm 1.5$ & $1.5 \pm 0.8$ & $1.3 \pm 2.3$ \\
\hline DH5 $\alpha$ pro K12 & ND & 0 & ND & 0 \\
\hline ER2267 K12 & $\mathrm{ND}$ & 0 & ND & 0 \\
\hline DEC 1A O55:H6 & $1.3 \pm 1$ & $4.2 \pm 0.4$ & $3.6 \pm 0.3$ & $4.8 \pm 0.2$ \\
\hline DEC 2A O55:H6 & $1.4 \pm 1$ & $4.6 \pm 0.4$ & $4.2 \pm 0.3$ & $5.2 \pm 0.3$ \\
\hline DEC 4A O157:H7 & $3.8 \pm 0.2$ & $5.6 \pm 0.2$ & $5.2 \pm 0.2$ & $6.1 \pm 0.3$ \\
\hline DEC 4C 0157:H7 & $3.2 \pm 0.5$ & $5.3 \pm 0.2$ & $4.6 \pm 0.3$ & $6.1 \pm 0.3$ \\
\hline DEC 7D O157:H43 & ND & $5.9 \pm 0.2$ & ND & $6.0 \pm 0.2$ \\
\hline DEC 8D O111:H11 & $3.0 \pm 0.4$ & $5.0 \pm 0.2$ & $4.7 \pm 0.2$ & $6.1 \pm 0.3$ \\
\hline DEC 9C O26:HN & $1.2 \pm 1$ & $5.1 \pm 0.2$ & $3.8 \pm 0.2$ & $5.5 \pm 0.5$ \\
\hline DEC 11D O128:H2 & ND & $5.2 \pm 0.5$ & ND & $5.5 \pm 0.7$ \\
\hline DEC 13D O128:H7 & ND & $5.8 \pm 0.3$ & ND & $5.6 \pm 0.6$ \\
\hline DEC 15D 0111:H21 & ND & $4.9 \pm 0.5$ & ND & $5.5 \pm 0.5$ \\
\hline $86-24 \mathrm{O} 157: \mathrm{H} 7$ & ND & $4.2 \pm 0.7$ & ND & $5.6 \pm 0.3$ \\
\hline
\end{tabular}

${ }^{a}$ Mean $\log _{10}$ number of bacteria recovered per sprout or per seed coat after incubation for the number of days indicated. ND $=$ not determined; $0=$ no bound bacteria were detected. Sprouts were inoculated with approximately $10^{3}$ bacteria/ml. Numbers given are the mean $\log _{10}$ of the number of viable bacteria recovered per washed sprout or seed coat \pm standard deviation of a minimum of three experiments. The average sprout weighed approximately $50 \mathrm{mg}$ and the average opened seed coat approximately $5 \mathrm{mg}$. In all cases, the numbers of bacteria recovered from the wash water (second wash) were less than $5 \%$ of the numbers recovered from the sprout or seed coat. 
and 3). Some DEC strains, such as 7D, bound only to the epidermis. Others, such as 4A, bound to both the epidermis and root hairs (Fig. 3). The bacteria also bound to the root tip (Fig. 2). All pathogenic strains examined bound to open seed coats (Fig. 4; Table 2). DEC 4A showed a reduced level of binding to spinach leaves (Table 3 ). When alfalfa leaves were examined using the fluorescent microscope, bacteria were seen inside the stomata where they would be unlikely to be removed by washing (Fig 5). It is difficult to determine whether the bacteria actually are bound to the plant cells in this location. K12 strains failed to show significant binding to any of these plant surfaces (Table 3).

Because the DEC strains examined showed larger numbers of bacteria bound to root tissue than to shoot or leaf tissue in microscopic observations, we examined the binding of DEC strains $4 \mathrm{~A}$ and $8 \mathrm{D}$ and $86-24$ to shoots and roots of alfalfa sprouts. Both strains 4A and 8D (Fig. 3) showed larger numbers of bacteria bound to the root $\left(10^{4.9}\right.$ and $\left.10^{5.1}\right)$ than to the shoot $\left(10^{3.8}\right.$ and $\left.10^{3.9}\right)$. However, this difference does not appear to be a general property of pathogenic strains of $E$. coli because strain 86-24 showed roughly equal numbers of bacteria bound to the root $\left(10^{4.6}\right)$ and shoot $\left(10^{4.2}\right)$.
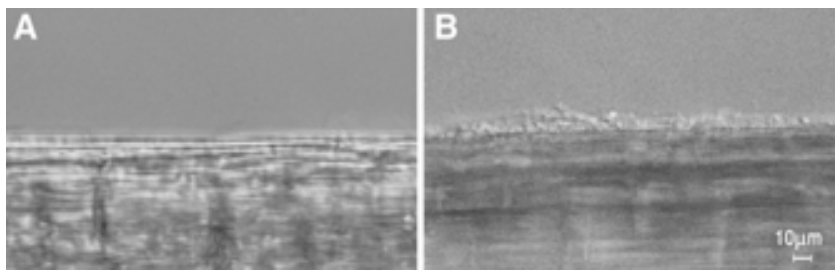

Fig. 1. Photomicrograph showing $\mathbf{A}$, an alfalfa root incubated without bacteria and B, diarrheagenic Escherichia coli 7D (O157:H43) bound to the alfalfa root epidermis after 3 days of incubation. The bacteria form a thin layer 1 to 3 cells deep on the root surface.
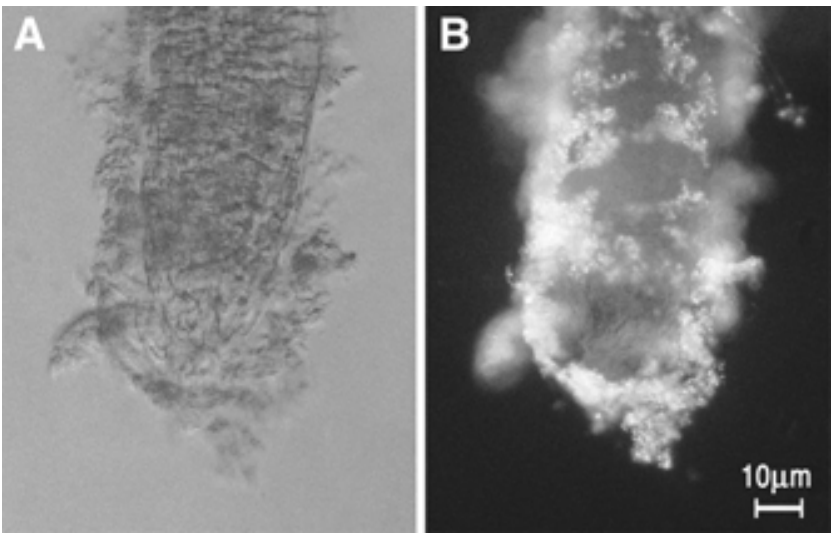

Fig. 2. A, Light and B, fluorescence photomicrographs showing diarrheagenic Escherichia coli $8 \mathrm{D}$ pBCgfp $(\mathrm{O} 111: \mathrm{H} 11)$ bound to the epidermis and sloughing epidermal cells at the root tip of an Arabidopsis thaliana plant.

\section{Binding of an avian pathogenic strain.}

An avian pathogenic strain of $E$. coli (APEC) which uses curli to bind to animal cells was identified previously by Brown and associates (2001). In addition, a clone from this APEC strain of a positive regulator of curli gene expression was shown to cause a K12 strain to produce curli and bind to animal cells. These properties suggested that it would be interesting to examine the interaction of this APEC strain, $\chi 7122$, with plant surfaces. Strain $\chi 7122$ showed significant binding to both sprouts and seed coats (Table 4). Curli expression requires the gene for the major protein of curli, $\operatorname{csg} A$, and is positively regulated by $r p o S$ (the stationary phase sigma factor) and $m l r A$ (Brown et al. 2001). The ability of $\chi 7122$ with mutations in each of these genes to bind to sprouts was examined. No significant reduction in binding was seen with the $m l r A$ mutation (Table 4). The RpoS and CsgA mutants showed a 10-fold reduction in binding to sprouts which was only marginally significant (no change in binding to seed coats was observed). However, when binding of the parent strain and the rpoS mutant to A. thaliana roots was examined in the microscope, the binding appeared different. The parent strain bound as a loose network of bacteria spread along the surface of the epidermis. The rpoS mutant bound as tight clusters of bacteria (Fig. 6). Binding of the CsgA and MlrA mutants appeared normal (data not shown).

E. coli K12 HB101 ordinarily does not synthesize curli or cause mannose resistant hemagglutination (MHRA). Brown and associates (2001) reported that, when the $m l r A$ gene from $\chi 7122$ was introduced into HB101 on a plasmid, it allowed the bacteria to synthesize curli and cause MRHA. We examined
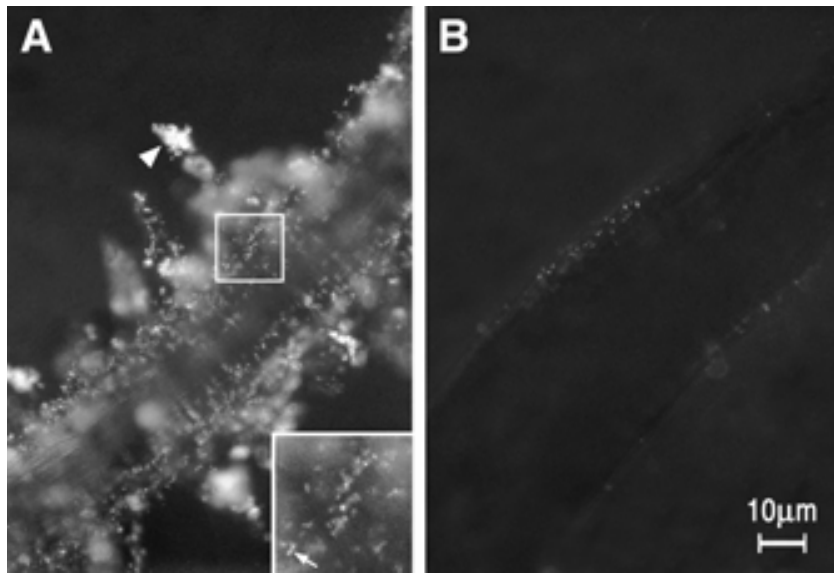

Fig. 3. Fluorescence photomicrographs showing diarrheagenic Escherichia coli (DEC) 8D pBCgfp (O111:H11) on A, the surface of a root of Arabidopsis and $\mathbf{B}$, the stem of the same plant. Note the presence of bacterial aggregates on the surface of the epidermis and on the root hairs (arrowhead) (seen here as projections from the root surface). Individual bound bacteria are indicated by the arrow in the inset. All of the DEC strains showed large numbers of bacteria bound to the root and very few bacteria bound to the shoot for alfalfa, tomato, and Arabidopsis thaliana. The enterohemorrahagic E. coli $86-24$ showed greater binding to the shoot than did the DEC strains.

Table 3. Binding of E. coli $\mathrm{K} 12$ and $\mathrm{O} 157: \mathrm{H} 7$ to various plants and plant organs

\begin{tabular}{|c|c|c|c|c|c|c|}
\hline \multirow[b]{3}{*}{ Bacterial strain } & \multicolumn{6}{|c|}{ Mean $\log _{10}$ number of bacteria recovered from the plant tissue ${ }^{a}$} \\
\hline & \multicolumn{2}{|c|}{ Tomato seedlings } & \multicolumn{2}{|c|}{ Spinach leaves (bacteria/cm²) } & \multicolumn{2}{|c|}{ Arabidopsis thaliana whole plants } \\
\hline & 1 day & 3 days & 1 day & 3 days & 1 day & 3 days \\
\hline H39 (K12) & $0.5 \pm 0.5$ & $1.0 \pm 0.9$ & $0.1 \pm 0.1$ & $0.1 \pm 0.1$ & $0.1 \pm 0.1$ & $0.1 \pm 0.1$ \\
\hline DEC4A (O157:H7) & $4.1 \pm 0.7$ & $6.5 \pm 0.6$ & $0.1 \pm 0.1$ & $3.2 \pm 0.2$ & $2.0 \pm 0.3$ & $6.2 \pm 0.3$ \\
\hline
\end{tabular}

${ }^{a}$ Numbers given are the mean $\log _{10}$ of the number of viable bacteria recovered per washed plant or leaf segment \pm standard deviation of a minimum of three experiments. 
the ability of HB101 carrying this plasmid (pYA3404) and HB101 pUC18 to bind to alfalfa sprouts (Table 4). HB101 pUC18 failed to show significant binding to sprouts or seed coats. However, HB101 pYA3404 was able to bind to sprouts and seed coats. The numbers of bacteria bound $\left(10^{2}\right.$ to $10^{3} /$ sprout) were intermediate between the number of HB101 pUC18 bound (less than 10/sprout) and the number of $\chi 7122$ bound (approximately $10^{5}$ /sprout).

\section{Binding of K12 strains carrying genes for curli.}

To determine whether the binding of HB101 pYA3404 was due to the synthesis of curli by HB101 or of some other surface component regulated by $m l r A$, we examined the ability of two K12 strains (ER2267 and DH5apro) carrying a plasmid with the genes for curli biosynthesis for their ability to bind to sprouts. Neither K12 strain tested showed detectable binding to alfalfa sprouts or open seed coats in the absence of introduced plasmids carrying genes for curli (Table 5). The plasmid pRMinv carries two operons containing the genes for the production of curli (Gophna et al. 2001). Its presence has been shown to cause K12 strains to synthesize curli and to exhibit an invasive phenotype (Gophna and Ron 2003). When this plasmid was introduced in DH5 $\alpha$ pro or ER2267, it allowed these strains to bind to alfalfa sprouts and open seed coats. The binding of these bacteria was not significantly different than that of pathogenic strains (Table $5)$. In the light microscope, the binding of the K12 strains carrying pRMinv appeared similar to that of $\chi 7122$ (data not shown).

\section{Binding of CsgA mutants of diarrheagenic strains.}

The ability of E. coli K12 strains with plasmids carrying the genes for the production of curli to bind to plants suggested that it would be interesting to examine the affects of a $\operatorname{csg} A$ mutation on binding by pathogenic strains. CsgA mutants were constructed in two O157:H7 human-pathogenic strains, DEC 4A and 86-24. Neither of these CsgA mutants showed significant reduction in binding to sprouts (parent strains bound $10^{4.2}$ and $10^{5.6}$ bacteria whereas the mutants bound $10^{4.1}$ and $10^{5.1}$, respectively). In the light microscope, no change was observed in the binding of these mutants to A. thaliana roots when compared with binding of the parent strains (data not shown). Thus, it appears that, although the genes encoding the production of curli are sufficient to allow K12 strains to bind to sprouts, they are not required for the binding of diarrheagenic strains.
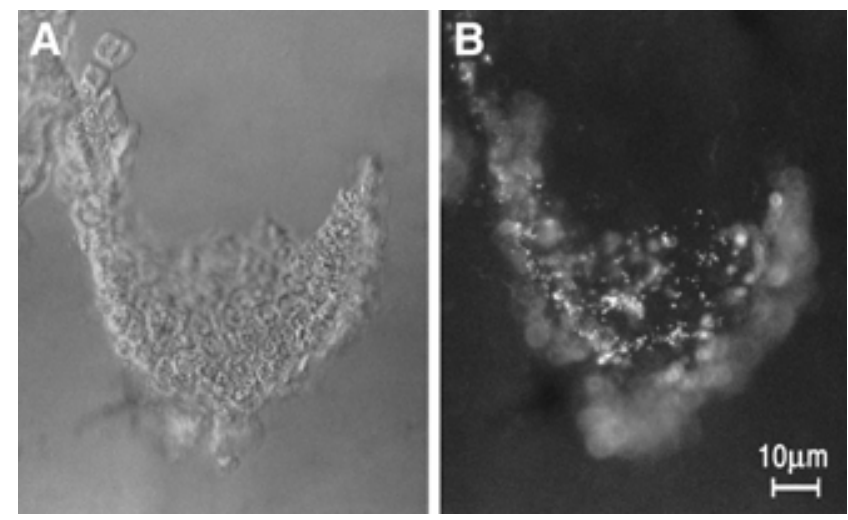

Fig. 4. A, Light and B, fluorescence photomicrographs showing diarrheagenic Escherichia coli (DEC) 4A pBCgfp (O157:H7) bound to an Arabidopsis thaliana open seed coat. Bacteria bound to the outer and inner surface of the seed coat. Binding to alfalfa and Arabidopsis seed coats appeared similar for all DEC strains.
Relationship between bacterial growth and binding.

The only source of nutrients when bacteria are incubated with sprouts in water is the sprouts themselves and their open seed coats. Pathogenic strains that bound to sprouts showed an increase in the number of free bacteria in the water. K12 strains that failed to bind to sprouts also failed to show this increase in the numbers of free bacteria. These observations raise the question of whether the lack of growth of the K12 strains results in their failure to bind or the failure to bind results in their lack of growth. The existence of K12 strains that bind to sprouts only when they contain a plasmid encoding the genes for the production of curli allowed us to use these strains and isogenic strains carrying empty plasmid vectors to examine the relationship between bacterial binding and growth.

When the number of free bacteria in the water is measured after 3 days of incubation with sprouts, most strains which bind to sprouts have grown from the initial inoculum of approximately $8 \times 10^{3}$ bacteria per milliliter to between $10^{6}$ and $10^{7}$ bacteria per milliliter (Table 6). K12 strains which fail to bind to sprouts show little, if any, growth during the incubation with sprouts. However, E. coli strains, whether not they bind to sprouts, do derive sufficient nutrition from the sprouts to maintain viability. Approximately 50 to $99 \%$ of bacteria of the tested strains incubated in water without sprouts died after 3 days, whereas bacteria incubated in water with sprouts retained their initial cell number (Table 6). The effect of adding nutrients to the medium was examined. The addition of more than very dilute salts and glucose to the medium adversely affected the growth of alfalfa sprouts; therefore, a 1 to 10 dilution of Murashige and Skoog plant tissue culture salts containing $0.02 \%$ glucose was used. The growth of the alfalfa sprouts appeared unaltered in this medium. No effect on the growth or binding of DEC 4A, ER2267 pRMinv, or ER2267 pBBRmcs-5 was observed. The growth of the K12 strain H39 was increased in this medium but H39
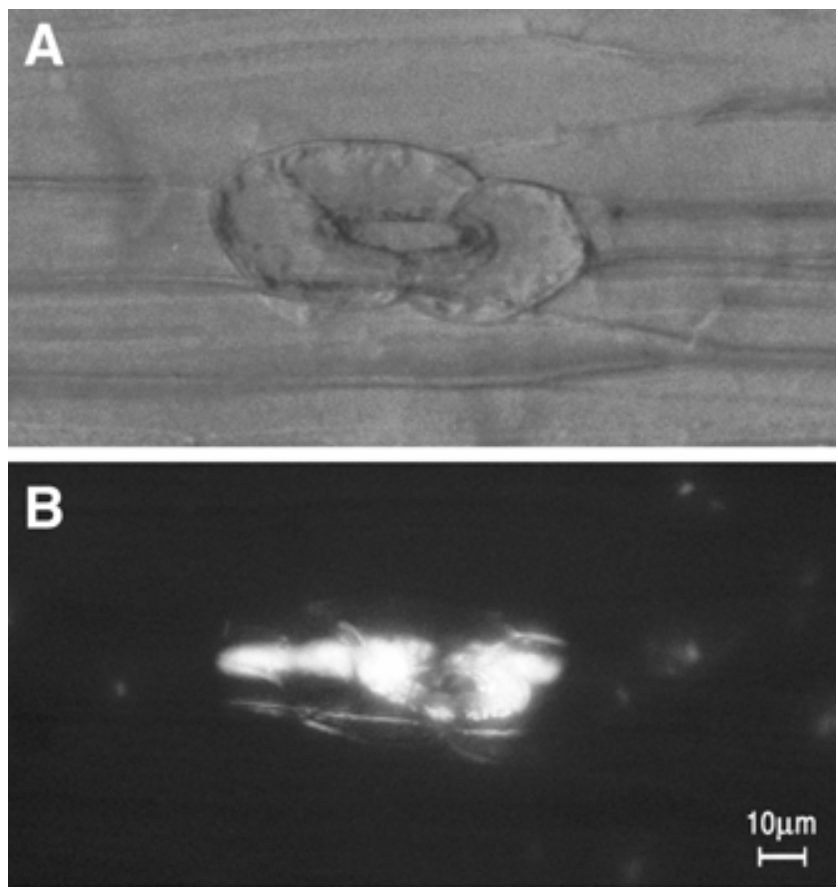

Fig. 5. A, Light and B, fluorescence photomicrographs showing diarrheagenic Escherichia coli 4A pBCgfp (O157:H7) inside a stomatum on an alfalfa leaf. Bacteria on other locations on the shoot were removed by washing but those inside the stomata could not be washed off. Less than $1 \%$ of the stomata contained bacteria. 
still failed to show significant binding to either sprouts or open seed coats (Table 6), suggesting that the lack of binding was not due to lack of growth.

When the growth of K12 strains containing pRMinv was compared with the same strains carrying plasmids without a cloned insert, only the strains carrying pRMinv bound to sprouts and only these strains showed an increase in the number of free bacteria in the water surrounding the sprouts. It seemed possible that bacterial binding to sprouts might stimulate the plants to release increased nutrients into the medium, supporting increased bacterial growth. In order to examine this possibility, sprouts were incubated with both ER2267 pRMinv and ER2267 pBBRmcs-5 added together to in the same dish. The incubation of the bacteria together had no significant affect on the growth or binding of either strain (Table 6). Similar results were obtained when the plasmid pBBRmcs-5 was replaced by

Table 4. Binding of an avian pathogenic strain, and mutants and clones derived from it

\begin{tabular}{|c|c|c|c|}
\hline \multirow[b]{2}{*}{ Bacterial strain } & \multirow[b]{2}{*}{ Genotype } & \multicolumn{2}{|c|}{$\begin{array}{c}\text { Mean } \log _{10} \text { number of } \\
\text { bacteria recovered }^{\mathrm{a}}\end{array}$} \\
\hline & & Per sprout & Per seed coat \\
\hline$\chi 7122$ & Wild type & $5.3 \pm 0.3$ & $5.6 \pm 0.4$ \\
\hline$\chi 7149$ & $r p o S^{-}$ & $4.4 \pm 0.2$ & $5.6 \pm 0.4$ \\
\hline$\chi 7185$ & $m l r A^{-}$ & $4.6 \pm 0.8$ & $5.4 \pm 0.4$ \\
\hline$\chi 7186$ & $\operatorname{csg} A^{-}$ & $4.3 \pm 0.6$ & $4.7 \pm 0.9$ \\
\hline HB101 pUC18 & K12 wild type & $0.6 \pm 1.0$ & 0 \\
\hline HB101 pYA3404 & $m l r A^{+}$ & $2.6 \pm 0.4$ & $3.3 \pm 1.0$ \\
\hline
\end{tabular}

${ }^{a}$ Sprouts were inoculated with approximately $10^{3}$ bacteria/ml. Numbers given are the mean $\log _{10}$ of the number of viable bacteria recovered from the homogenate of washed sprouts or seed coats \pm standard deviation of a minimum of three experiments. The average sprout weighed approximately $50 \mathrm{mg}$ and the average opened seed coat approximately 5 $\mathrm{mg}$. In all cases, the numbers of bacteria recovered from the wash water (second wash) were less than $1 \%$ of the number recovered from the sprout or seed coat; $0=$ no bacteria were detected bound to seed coats.
pBluescript KS- (data not shown). These results again suggest that the lack of binding was not due to lack of bacterial growth but that binding increased bacterial growth.

\section{DISCUSSION}

The binding of DEC to alfalfa sprouts described in this study is comparable to that seen in other studies. In general, binding of these bacteria is slow. Barak and associates (Barak 2002) were unable to detect binding of $E$. coli after $4 \mathrm{~h}$ of incubation with sprouts in water, although binding of Salmonella enterica was detectable. We also were unable to detect binding after short incubation times $(6 \mathrm{~h})$. Many of the strains we examined showed increasing numbers of bacteria bound during the interval between 1 and 3 days of incubation. This increase may represent a combination of growth of bound bacteria and binding of growing planktonic bacteria. Measurements of sugars released by the sprouts into the irrigation wa-

Table 5. Effect of pRMinv on the binding of Escherichia coli K12 strains

\begin{tabular}{llc}
\hline & \multicolumn{2}{c}{$\begin{array}{c}\text { Mean } \log _{\mathbf{1 0}} \text { number of bacteria } \\
\text { recovered after 3 days of incubation }\end{array}$} \\
\cline { 2 - 3 } Bacterial strain & Per sprout & Per seed coat $^{\text {rat }}$ \\
\hline DH5 $\alpha$ pro & 0 & 0 \\
DH5 $\alpha$ pro pRMinv & $3.7 \pm 0.6$ & $4.1 \pm 0.5$ \\
ER2267 & 0 & 0 \\
ER2267 pRMinv & $5.6 \pm 0.2$ & $5.8 \pm 0.3$ \\
\hline
\end{tabular}

${ }^{a}$ Sprouts were inoculated with approximately $10^{3}$ bacteria $/ \mathrm{ml}$. Numbers given are the mean $\log _{10}$ of the number of viable bacteria recovered from the homogenate of washed sprouts or seed coats \pm standard deviation of a minimum of three experiments. The average sprout weighed approximately $50 \mathrm{mg}$ and the average opened seed coat approximately 5 $\mathrm{mg}$. In all cases, the numbers of bacteria recovered from the wash water (second wash) were less than $1 \%$ of the number recovered from the sprout or seed coat; $0=$ no bacteria were detected.
$20 \mathrm{hrs}$
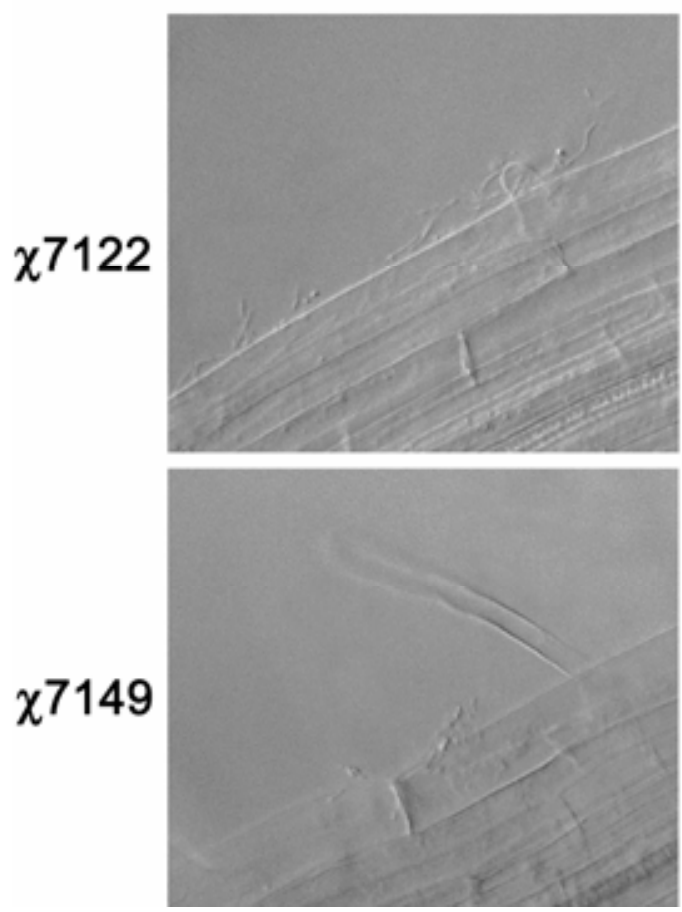

$48 \mathrm{hrs}$
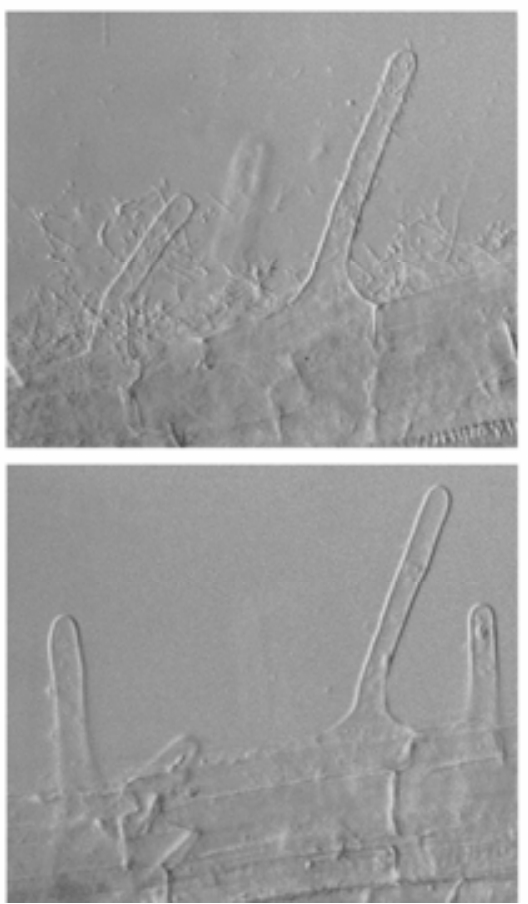

$72 \mathrm{hrs}$
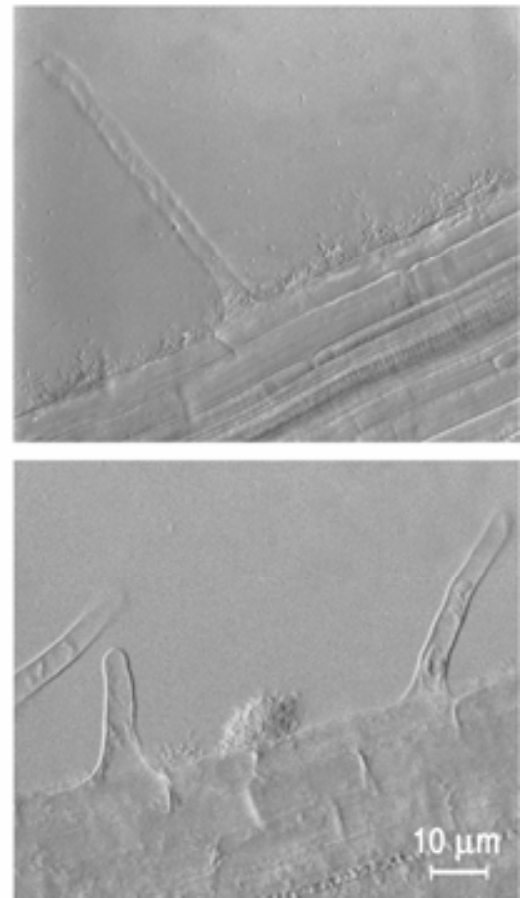

Fig. 6. Photomicrographs of avian pathogenic Escherichia coli incubated with Arabidopsis thaliana in water; $\chi 7122=$ wild-type parent strain and $\chi 7149=$ rpoS mutant. The wild-type parent strain bound as a diffuse layer on the epidermis. The rpoS mutant bound as aggregates of bacteria. Thus, although the numbers of bacteria bound were the same, the binding of the two types of bacteria appeared to be distinct. 
ter have suggested that most sugar is released at the beginning stages of germination and that, by 4 days, little additional nutrient is released (Howard and Hutcheson 2003). Our day 3 of incubation of sprouts with bacteria is the fourth day after germination because we did not inoculate the sprouts until they were 1 day old. Thus, our growth measurements agree well with the measurements of likely available nutrients.

We observed DEC strains bound to the root hairs and epidermis, which also has been seen by other researchers working with O157:H7 strains (Barak et al. 2002; Charkowski et al. 2002). The pattern of binding was dependent on the strain examined. All strains examined bound to the epidermis. In addition, some strains (for example, DEC 4A) bound to root hairs. Autoaggregative strains such as $8 \mathrm{D}$ bound to the root epidermis and hairs in clusters whereas nonaggregative strains such as $7 \mathrm{D}$ formed shallow layers coating the surface of the epidermis and showed little binding to root hairs. Most DEC strains showed a preference for binding to roots as opposed to shoots. However, some strains, such as 86-24, did not show this preference, suggesting that the mechanism of binding of different strains may not be identical. Some bacteria were seen inside the stomata of alfalfa leaves. E. coli previously have been observed inside the stomata of radish sprouts (Itoh et al. 1998). There was no correlation between serotype or source of the DEC strain with the site of binding or number of bacteria bound. Growth of E. coli in the rhizosphere and inside the plant has been observed using alfalfa plants grown in agar with Jensen's N-free medium (Dong et al. 2003). Using this system, fewer bacteria were seen in the rhizosphere than was the case in our water-grown sprouts. Approximately $10^{6} \mathrm{bacteria} / \mathrm{g}$ of alfalfa were observed in the rhizosphere of agar-grown sprouts. This number includes both root-associated bacteria removable by washing and bound bacteria. We observed approximately $10^{4}$ to $10^{6}$ bacteria bound per washed sprout (the average sprout weighed approximately $50 \mathrm{mg}$ at the time of harvest). The interior of the plants carried approximately $10^{3}$ bacteria per gram of alfalfa in the agar system. This number of bacteria (which would have been fewer than 100 bacteria per sprout) may have been too small for us to detect in the fluorescent microscope. We observed bacteria inside the sprouts only at wounded or damaged sites.

It is apparent from our data that open seed coats are a significant source of bacteria, as well as the sprouts themselves. This may be because the seed coats, although small, are senes- cent tissue and therefore may release more nutrients than the growing sprouts.

The experiments measuring binding of E. coli described above were carried out with axenic sprouts. However, most sprouts develop a natural biofilm of bacteria shortly after they germinate. When surface-sterilized seed are germinated in a densely packed dish, they rapidly become covered with a biofilm derived from organisms present underneath the seed coat of occasional infected seed. We measured the effects of this biofilm on the binding of DEC strains 4A and 8D carrying the plasmid $\mathrm{pBC} g f p$. The biofilm had little effect on binding after either 1 or 3 days (the average number of bacteria bound differed by less than a factor of 2 and was not statistically significant). The other bacteria present in the biofilm apparently neither inhibited nor promoted the binding of the DEC strain.

The ability of DEC to bind to plant surfaces appears not to be restricted to alfalfa sprouts. The bacteria bound well to tomato and A. thaliana seedlings and showed reduced but significant binding to spinach leaves. Colonization of $A$. thaliana growing in agar or soil has been observed by Cooley and associates (2003). Roots of plants growing in agar or soil appeared to have numbers of bacteria similar to those we observed on roots of plants incubated in water (approximately $10^{9}$ bacteria per gram for unwashed plants grown in agar) (Cooley et al. 2003); our plants weighed between 5 and $10 \mathrm{mg}$ each and had between $10^{6}$ and $10^{7}$ bacteria on each washed plant.

K12 strains failed to show significant binding to any of the plant surfaces tested under any of the conditions used. The failure of K12 strains to bind to plants suggests that some of the genes involved in the pathogenic interaction with human or mammalian hosts also might be involved in the ability of the bacteria to bind to plant surfaces. It also is possible that pathogenic strains possess a unique and uncharacterized system for binding to plant surfaces.

The role of curli in bacterial binding to sprouts was examined. Many pathogenic strains of E. coli make curli (Collinson et al. 1996; Romling et al. 1998; Zogaj et al. 2003). K12 strains, although they may posses the genes for curli production, generally don't make curli (Brown et al. 2001). The addition of a plasmid which caused the K12 strains to make curli allowed these bacteria to bind to spouts and open seed coats. This binding was not significantly different than the binding of pathogenic strains either in numbers of bacteria bound or in microscopic appearance or location of bound bacteria.

Table 6. Relationship between bacterial binding and bacterial growth

\begin{tabular}{|c|c|c|}
\hline \multirow[b]{2}{*}{ Conditions, bacterial strain } & \multicolumn{2}{|c|}{ Mean $\log _{10}$ number of bacteria ${ }^{a}$} \\
\hline & Free bacteria/ml & Bound bacteria/sprout \\
\hline \multicolumn{3}{|l|}{$5 \mathrm{ml}$ of water } \\
\hline $\mathrm{H} 39$ & $3.5 \pm 0.2$ & NA \\
\hline DEC 4A & $0.3 \pm 0.2$ & NA \\
\hline ER2267 pBBRmcs-5 & $2.3 \pm 0.3$ & NA \\
\hline ER2267 pRMinv & $2.3 \pm 0.3$ & NA \\
\hline \multicolumn{3}{|l|}{$5 \mathrm{ml}$ of water and sprouts } \\
\hline H39 & $4.1 \pm 0.2$ & $1.6 \pm 1.4$ \\
\hline DEC 4A & $7.6 \pm 0.5$ & $5.6 \pm 0.2$ \\
\hline ER2267 pBBRmcs-5 & $3.3 \pm 0.3$ & $1.3 \pm 1.2$ \\
\hline ER2267 pMMB33 & $3.5 \pm 0.5$ & $1.5 \pm 1.5$ \\
\hline ER2267 pRMinv & $6.0 \pm 0.4$ & $4.3 \pm 0.2$ \\
\hline \multicolumn{3}{|c|}{$5 \mathrm{ml}$ of $1 / 10$ Murashige and Skoog salts, $0.2 \%$ glucose, and sprouts } \\
\hline H39 & $5.0 \pm 0.4$ & $0 \pm 0.1$ \\
\hline $\mathrm{DEC} 4 \mathrm{~A}$ & $7.3 \pm 0.5$ & $5.8 \pm 0.3$ \\
\hline ER2267 pBBRmcs-5 & $3.8 \pm 0.5$ & $0.6 \pm 0.6$ \\
\hline ER2267 pRMinv & $6.4 \pm 0.5$ & $4.3 \pm 0.4$ \\
\hline \multicolumn{3}{|c|}{$5 \mathrm{ml}$ of water and sprouts and both bacterial strains added together } \\
\hline ER2267 pBBRmcs-5 & $3.6 \pm 0.3$ & $0.1 \pm 0.1$ \\
\hline ER2267 pRMinv & $6.5 \pm 0.4$ & $3.6 \pm 0.2$ \\
\hline
\end{tabular}

${ }^{\mathrm{a}} \mathrm{NA}=$ not applicable. 
When mutants of pathogenic strains which are unable to synthesize curli were examined, they showed no significant reduction in their ability to bind to sprouts or seed coats. Thus, although the production of curli is sufficient to allow K12 strains to bind to sprouts and seed coats, curli are not required for the binding of pathogenic strains. These strains may have a second alternative mechanism for binding to plant surfaces which is functional in the absence of curli.

Bacteria incubated with sprouts in water must get all of their nutrients from the sprouts. More than $50 \%$ of both pathogenic and K12 strains of E. coli die if incubated in water alone for 3 days. In the presence of sprouts, all strains tested retained viability. Those bacteria which bound to sprouts grew better than those which were unable to bind. The reasons for this are unclear; however, increased growth may be due in part to increased nutrient availability at the surface of the roots.

When the binding of $E$. coli to alfalfa is compared with the binding of the plant-pathogenic Agrobacterium tumefaciens or the alfalfa symbiont Sinorhizobium meliloti, the most notable differences are the slowness with which $E$. coli binds and the sites of binding to the roots. A. tumefaciens shows detectable binding to alfalfa in $2 \mathrm{~h}$ and Sinorhizobium meliloti shows binding within $6 \mathrm{~h}$, whereas $24 \mathrm{~h}$ was required for $E$. coli binding. A. tumefaciens binds to epidermis and root hairs. It binds particularly well to cut ends of roots and other wound sites. Sinorhizobium meliloti binds to root hairs and also to root epidermis. It fails to bind to wound sites. Neither A. tumefaciens nor Sinorhizobium meliloti bind to the root tip. Both bacteria bind poorly to the shoot (Matthysse and Kijne 1998; A. G. Matthysse, unpublished observations). In contrast, all of the $E$. coli strains examined bound to the epidermis and root tip. Some, but not all, strains also bound to root hairs and to shoots. None of the E. coli strains examined bound to wound sites. Thus, it appears that at least some of the sites on the plant surface to which pathogenic E. coli bind are distinct from those to which A. tumefaciens or Sinorhizobium meliloti bind. It also appears that different $E$. coli strains have the ability to bind to different sites on the plant. These results, taken together with the results described above, suggest that DEC strains have multiple mechanisms for binding to plant surfaces and that different strains may have different subsets of genes involved in this binding and, thus, show varying binding characteristics.

\section{MATERIALS AND METHODS}

\section{Plant materials.}

Alfalfa sprouts were obtained by germinating seed. In order to ensure that the alfalfa sprouts were axenic, seed were surfacesterilized by soaking them briefly in $80 \%$ ethanol followed by $20 \mathrm{~min}$ in a $2.6 \%$ sodium hypochlorite solution containing Tween 80 as a wetting agent. The seed then were washed three times with sterile deionized water and germinated in small groups to avoid cross contamination from the occasional seed which contained bacteria or fungi underneath the seed coat. Approximately 1 in 30 seeds in our present seed lot had bacteria and fungi on the inside of the seed coat (this number is typical of most alfalfa seed lots); these organisms cannot be killed without harming the plant. For most experiments, seed were germinated in small batches (less than 10 seeds) and those batches which were contaminated were discarded. Contamination was determined by visual and microscopic examination and by plating a sample of the water surrounding the germinating seed on Luria agar. In those experiments in which we wished to obtain sprouts and seed coats which were covered with a biofilm derived from the bacteria found inside seed coats, seed were surface sterilized and germinated in crowded conditions (more than 100 seeds per petri dish). No E. coli appeared to be present in the natural biofilm as judged by the growth of bacteria recovered from it on McConkey agar. Surface-sterilized seed were germinated for 1 day in sterile water before inoculation with bacteria. Axenic tomato seedlings were obtained using a similar protocol, except that the seed were germinated for 4 days before the inoculation of bacteria. A. thaliana ecotype Columbia seed were surface sterilized using the same protocol. They then were suspended in $0.1 \%$ phytagar and placed at $4^{\circ} \mathrm{C}$ for 2 to 4 days before growth on the surface of $1.7 \%$ phytagar containing Murashige and Skoog salts (Gibco BRL, Grand Island, NY, U.S.A.). The plants were grown in an incubator on a 14-h day with the agar surface vertical so that the roots and shoots grew along the surface of the agar rather than into it. Plants with roots 2 to $4 \mathrm{~cm}$ long were removed from the agar surface, washed in sterile water, and incubated in sterile water for use in experiments. Spinach leaves were obtained from a local supermarket, washed with mild detergent and water, and cut into $1-\mathrm{cm}^{2}$ pieces before use.

\section{Inoculation and harvesting of sprouts and seed coats.}

After germination, sprouts, seedlings, or leaf pieces were put into plastic dishes in groups of four with $5 \mathrm{ml}$ of sterile deionized water. Bacteria were diluted and added to the germinated seed to a final concentration of approximately $8 \times 10^{3}$ bacteria per milliliter. Sprouts and seed coats were analyzed separately. Each was washed twice by vigorous inversions in 5 $\mathrm{ml}$ of sterile deionized water. The sprout or seed coat then was homogenized in $5 \mathrm{ml}$ of washing buffer (Loper et al. 1984) in a Teflon glass homogenizer and plated to determine viable cell counts. For those experiments in which binding to shoots and roots was measured separately, the root was cut from the shoot after the second wash. Results are reported as the $\log _{10}$ number of bacteria per sprout or seed coat.

\section{Microscopy.}

For microscopic examination, roots or plants were rinsed by dipping them in sterile water, then mounted in water on microscope slides. Press-apply cover slips were used to mount intact alfalfa sprouts. Photomicroscopy was carried out using living material and a Nikon microscope. Nomarski optics were used for visible light microscopy. Fluorescence microscopy used 488-nm excitation and 520-nm emission wavelengths. No green fluorescence was observed from the roots or bacteria in the absence of bacteria carrying the $g f p$ gene. The level of fluorescence was markedly increased by the addition of isopropylthio- $\beta$-D-galactoside (IPTG) to mixtures containing bacteria carrying the $g f p$ gene behind the lac promoter.

\section{Growth of bacteria.}

Bacteria were grown in Luria broth or on Luria or McConkey agar at $37^{\circ} \mathrm{C}$. The strains used and their characteristics and sources are listed in Table 1. Antibiotics were added at the following final concentrations: chloramphenicol at $30 \mu \mathrm{g} / \mathrm{ml}$, streptomycin at $500 \mu \mathrm{g} / \mathrm{ml}$, ampicillin at $60 \mu \mathrm{g} / \mathrm{ml}$, kanamycin at $20 \mu \mathrm{g} / \mathrm{ml}$, rifampicin at $50 \mu \mathrm{g} / \mathrm{ml}$, and neomycin at $60 \mu \mathrm{g} / \mathrm{ml}$ in agar and $20 \mu \mathrm{g} / \mathrm{ml}$ in liquid (antibiotics never were added in the presence of the plant). For strains lacking an antibiotic resistance marker, the number of bacteria recovered on Luria agar and McConkey agar were the same. On McConkey agar, all of the recovered bacteria appeared to be E. coli. No E. coli were recovered on McConkey agar from sprouts which had not been inoculated with $E$. coli. Spontaneous rifampicin-resistant mutants of K12 strains and DEC strains were isolated and used in some experiments. The growth and binding of these mutants did not differ from that of the parent strain. The plasmid pBCgfp (Matthysse et al. 1996) was introduced into various 
strains by $\mathrm{CaCl}_{2}$-mediated transformation. Expression of the $g f p$ gene was induced by the addition of IPTG to a final concentration of $0.2 \mathrm{mg} / \mathrm{ml}$ followed by incubation for $20 \mathrm{~h}$. Plasmids were introduced into $E$. coli by calcium-mediated transformation. The presence of pRMinv was found to result in bacteria which showed increased staining with Congo red as expected of strains producing curli (Chapman et al. 2002). No difference in the rate of growth of $E$. coli carrying pRMinv compared with pBBRmcs-5 was observed in Luria broth.

\section{Construction of csgA mutants.}

Mutants in the $\operatorname{csg} A$ gene were constructed by interrupting the gene with a plasmid. A 300-bp fragment of $\operatorname{csg} A$ was obtained by polymerase chain reaction (PCR) using primers located within the open reading frame of the gene. The primers were 5'-GCAGAAGCTTGGTGTTGTTCCTCAGTACGG-3' and 5'-CGTCGAGGATCCGCACCGTTGCACCACCG-3'. Italics indicate the HindIII and BamHI sites which were used to clone the PCR fragment into pBluescript KS-. The plasmid pUTgfp was modified by digesting it with XhoI followed by religation of the digested plasmid (Matthysse et al. 1996). This resulted in the deletion of the left end of the transposon, includeing the tetracycline resistance gene and the first half of the transposase open reading frame; the resulting plasmid was named pUTgfp $\Delta X h o$. The pir-dependent origin of replication was maintained. The PCR fragment obtained from $\operatorname{csg} A$ was cut from pBluescript KS- using KpnI and SacI and cloned between the KpnI and $S a c$ I sites in pUTgfp $\Delta X h o$ and the plasmid transformed into $E$. coli $\mathrm{S} 17$ ( pir $\left.^{+}\right)$. It is unable to replicate in wild-type $E$. coli strains that lack the pir gene. In order to construct $\operatorname{csg} A$ mutations in various $E$. coli strains, the plasmid was introduced into the strain by $\mathrm{CaCl}_{2}$-mediated transformation and bacteria in which the plasmid had integrated into the chromosome were selected using carbenicillin resistance encoded by the plasmid. The integration of the plasmid into the $\operatorname{csg} A$ gene was confirmed by PCR.

\section{ACKNOWLEDGMENTS}

This research was supported by United States Department of Agriculture grant number 2003-35201-13693 to A. G. Matthysse. We thank S. Whitmore for assistance with the figures, E. Moulton for assistance with some of the earlier experiments, and M. Farrer and S. Stager for general assistance.

\section{LITERATURE CITED}

Barak, J. D., Whitehand, L. C., and Charkowski, A. O. 2002. Differences in attachment of Salmonella enterica serovars and Escherichia coli O157:H7 to alfalfa sprouts. Appl. Environ. Microbiol. 68:47584763.

Brown, P., Dozois, C., Nickerson, C., Zuppardo, A., Terlonge, J., and Curtis, R. 2001. MlrA, a novel regulator of curli (AgF) and extracellular matrix synthesis by Escherichia coli and Salmonella enterica serovar Typhimurium. Mol. Microbiol. 41:349-363.

Chapman, M. R., Robinson, L. S., Pinkner, J. S., Roth, R., Heuser, J., Hammar, M., Normark, S., and Hultgren, S. J. 2002. Role of Escherichia coli curli operons in directing amyloid fiber formation. Science 295:851-855.

Charkowski, A. O., Barak, J. D., Sarreal, C. Z., and Mandrell, R. E. 2002. Differences in growth of Salmonella enterica and Escherichia coli $\mathrm{O} 157: \mathrm{H} 7$ on alfalfa sprouts. Appl. Environ. Microbiol. 68:31143120 .

Collinson, S. K., Clouthier, S. C., Doran, J. L., Banser, P. A., and Kay, W. W. 1996. Salmonella enteritidis agfBAC operon encoding thin, aggregative fimbriae. J. Bacteriol. 178:662-667.

Cooley, M. B., Miller, W. G., and Mandrell, R. E. 2003. Colonization of Arabidopsis thaliana with Salmonella enterica and enterohemorrhagic Escherichia coli $\mathrm{O} 157: \mathrm{H} 7$ and competition by Enterobacter asburiae. Appl. Environ. Microbiol. 69:4915-4926.

Dong, Y., Iniguez, A. L., Ahmer, B. M., and Triplett, E. W. 2003. Kinetics and strain specificity of rhizosphere and endophytic colonization by enteric bacteria on seedlings of Medicago sativa and Medicago truncatula. Appl. Environ. Microbiol. 69:1783-1790.

Gophna, U., Barlev, M., Seijffers, R., Oelschlager, T. A., Hacker, J., and Ron, E. Z. 2001. Curli fibers mediate internalization of Escherichia coli by eukaryotic cells. Infect. Immun. 69:2659-2665.

Gophna, U., and Ron, E. Z. 2003. Virulence and the heat shock response. Int. J. Med. Microbiol. 292:453-461.

Howard, M. B., and Hutcheson, S. W. 2003. Growth dynamics of Salmonella enterica strains on alfalfa sprouts and in waste seed irrigation water. Appl. Environ. Microbiol. 69:548-553.

Itoh, Y., Sugita-Konishi, Y., Kasuga, F., Iwaki, M., Hara-Kudo, Y., Saito, N., Noguchi, Y., Konuma, H., and Kumagai, S. 1998. Enterohemorrhagic Escherichia coli O157:H7 present in radish sprouts. Appl. Environ. Microbiol. 64:1532-1535.

Kovach, M. E., Elzer, P. H., Hill, D. S., Robertson, G. T., Farris, M. A., Roop, R. M., and Peterson, K. M. 1995. Four new derivatives of the broad-host-range cloning vector pBBR1MCS carrying different antibiotic-resistance cassettes. Gene 166:175-176.

Loper, J., Suslow, T., and Schroth, M. 1984. Lognormal distribution of bacterial populations in the rhizosphere. Phytopathology 74:1454-1460.

Mahon, B. E., Ponka, A., Hall, W. N., Komatsu, K., Dietrich, S. E., Siitonen, A., Cage, G., Hayes, P. S., Lambert-Fair, M. A., Bean, N. H., Griffin, P. M., and Slutsker, L. 1997. An international outbreak of Salmonella infections caused by alfalfa sprouts grown from contaminated seeds. J. Infect. Dis. 175:876-882.

Matthysse, A. G., and Kijne, J. W. 1998. Attachment of Rhizobiaceae to plant cells. Pages 235-249 in: The Rhizobiaceae. H. P. Spaink, A Kondorosi, and P. J. J. Hooykaas, eds. Kluwer Academic Publishers, Dordrecht, The Netherlands.

Matthysse, A. G., Stretton, S., Dandie, C., McClure, N. C., and Goodman, A. E. 1996. Construction of GFP vectors for use in gram-negative bacteria other than Escherichia coli. FEMS (Fed. Eur. Microbiol. Soc.) Microbiol. Lett. 145:87-94.

National Advisory Committee on Microbiological Criteria for Foods. 1999. Microbiological safety evaluations and recommendations on sprouted seeds. Int. J. Food Microbiol. 52:123-153.

Olsen, A., Jonsson, A., and Normark, S. 1989. Fibronectin binding mediated by a novel class of surface organelles on Escherichia coli. Nature 338:652-655.

Prokopowich, D., and Blank, G. 1991. Microbiological evaluation of vegetable sprouts and seeds. J. Food Prot. 54:560-562.

Puohiniemi, R., Heiskanen, T., and Siitonen, A. 1997. Molecular epidemiology of two international sprout-borne Salmonella outbreaks. J. Clin. Microbiol. 35:2487-2491.

Romling, U., Bian, Z., Hammar, M., Sierralta, W. D., and Normark, S. 1998. Curli fibers are highly conserved between Salmonella typhimurium and Escherichia coli with respect to operon structure and regulation. J. Bacteriol. 180:722-731.

Zogaj, X., Bokranz, W., Nimtz, M., and Romling, U. 2003. Production of cellulose and curli fimbriae by members of the family Enterobacteriaceae isolated from the human gastrointestinal tract. Infect. Immun. 71:4151-4158.

\section{AUTHOR-RECOMMENDED INTERNET RESOURCE}

Michigan State University STEC (Shiga toxin-producing E. coli) Center's DECA reference strain set webpage: www.shigatox.net/cgi-bin/deca 